\title{
Diálogo entre cortes en relación con los grupos vulnerables
}

Dialogue between courts in relation to vulnerable groups

\author{
Ab. Verónica Hernández Muñóz, Mgtr. \\ Docente titular UEES
}

Artículo Original (Revisión)

RFJ, No. 4, 2018, pp. 399-420, ISSN 2588-0837

\begin{abstract}
RESUMEN: en el presente artículo se buscará determinar la existencia de un diálogo entre cortes del tipo deliberativo, cuyo objetivo es la coordinación de actuaciones para conseguir un mejor curso de acción logrando una actuación eficaz y con menores efectos negativos y la relación de este con la protección de grupos vulnerables previstos en la Constitución ecuatoriana, para este análisis se toma como referencia las acciones extraordinarias de protección resueltas por la Corte Constitucional del Ecuador en el período 2008-2018, específicamente se han considerado cinco procesos en los que se hace referencia y cita de los criterios de la Corte Interamericana de Derechos Humanos emitidos en fallos u opiniones consultivas donde se resolvió a favor de un caso de género o en beneficio de personas pertenecientes a grupos de atención prioritaria. Se identificará, de esta manera en cada caso el precedente o regla jurisprudencial que los jueces constitucionales ecuatorianos dictaron bajo este contexto y que constituirán precedentes jurisprudenciales para su aplicación en el futuro.
\end{abstract}

PALABRAS CLAVE: derecho constitucional, acceso a la justicia, derecho al trabajo, sentencia judicial, derecho de grupos vulnerables.

ABSTRACT: In this article we will try to determine the existence of a dialogue between courts of the deliberative type, whose objective is the coordination of actions to achieve a better course of action achieving an effective action and with less negative effects and the relationship of this with the protection of vulnerable groups foreseen in the Ecuadorian constitution, for this analysis is taken as reference the extraordinary protection actions resolved by the Constitutional Court of Ecuador in the period 2008-2018, specifically five processes have been 
considered in which reference and appointment of the criteria of the Inter-American Court of Human Rights issued in rulings or advisory opinions where it was resolved in favor of a gender case or for the benefit of persons belonging to priority attention groups. This will identify, in each case, the precedent or jurisprudential rule that the Ecuadorian constitutional judges dictated in this context and that will constitute jurisprudential precedents for its application in the future.

KEY WORDS: constitutional law, access to justice, right to work, judicial decision, right of vulnerable groups..

\section{INTRODUCCIÓN}

El presente ensayo toma como referencia las acciones extraordinarias de protección resueltas por la Corte Constitucional del Ecuador en el período 2008-2018. El procedimiento realizado consistió en la lectura, análisis e identificación de un "diálogo entre Cortes" en casos resueltos a favor de los grupos de atención prioritaria y un caso de género. Se dice que existe diálogo cuando la Corte Constitucional del Ecuador cita sentencias y opiniones consultivas dictadas por la Corte Interamericana de Derechos Humanos para decidir. Para ello, se identificó, primero, los criterios internacionales que los jueces nacionales han citado. Responderá a la pregunta: ¿qué criterios de la Corte Interamericana de Derechos Humanos ha tomado la Corte Constitucional del Ecuador como referencia en los fallos seleccionados? Y, luego a propósito del diálogo jurisprudencial $¿$ se puede afirmar que existen criterios garantistas y evolutivos a la luz de la doctrina de derechos humanos en los casos de los grupos de atención prioritaria y en el caso de género?

Del universo de casos resueltos por la Corte Constitucional del Ecuador se tomaron como referencia aquellos que fueron iniciados por personas pertenecientes a un grupo de atención prioritaria y en el que la Corte Constitucional del Ecuador citó criterio de la Corte Interamericana de Derechos Humanos para decidir en beneficio de la persona necesitada de atención prioritaria, de los cuales se seleccionaron los siguientes:1) Caso de discriminación por causa por género. Sentencia No 292-16-SEP-CC, Caso No 0734-13-EP, del 7 de septiembre de 2016; 2) Asunto de persona privada de libertad en estado de gestación a quien se le negó el Habeas Corpus. Sentencia No 247-17-SEP-CC, Caso $\mathrm{N}^{\circ}$ 0012-12-EP, del 9 de agosto de 2017; 3) Asunto de despido de persona con enfermedad catastrófica. Sentencia No $375-17-S E P-C C$, 
Caso No 0526-13-EP del 22 de noviembre de 2017; 4) Negativa del Instituto Ecuatoriano de Seguridad Social de atender a menor de edad por no ser hijo de abuelo, a pesar que este era afiliado del Instituto de Seguridad Social y ejercía la tutela del niño- nieto. Sentencia $\mathrm{N}^{\circ}$ 380-17-SEP-CC, Caso No 2334-16-EP del 22 de noviembre de 2017; $y, 5)$ Despido intempestivo de una persona con discapacidad. Sentencia No 004-18-SEP-CC, Caso N. ${ }^{\circ} 0664-14-E P$, del 3 de enero de 2018, Estos casos fueron seleccionados por ser pertinentes al presente análisis. Para explicación, el ensayo contiene la estructura siguiente: 1) Características del Diálogo; 2) Desarrollo de casos con identificación de los criterios seleccionados; y, 3) Conclusión.

\section{REGLAS DEL DIÁLOGO}

La finalidad de cada tipo de diálogo presupone, respectivamente, una concreta situación inicial y un determinado objetivo en los participantes. Las reglas del diálogo entre Cortes podrían resumirse en las siguientes (Asociación de Letrados del Tribunal Constitucional, 2013)

a) En el diálogo persuasivo la situación inicial es un conflicto de opiniones; el objetivo de cada parte, persuadir a la otra; y la finalidad del diálogo, resolver o clarificar la cuestión.

b) En el diálogo de investigación la situación inicial es el planteamiento de una tesis; el objetivo de cada parte, encontrar o verificar la evidencia; y la finalidad del diálogo, probar o refutar la tesis.

c) En el diálogo de descubrimiento la situación inicial es la necesidad de explicación de un descubrimiento; el objetivo de las partes es hallar una hipótesis; y la finalidad del diálogo, fundamentar la hipótesis.

d) En la negociación la situación inicial es un conflicto de intereses; el objetivo de las partes, recibir lo que se desea cediendo lo menos posible; y la finalidad del diálogo, lograr un convenio razonable mutuamente aceptado.

e) En el diálogo informativo la situación inicial es la necesidad de información; el objetivo de las partes, adquirir o dar información obteniendo ventaja; y la finalidad del diálogo, el intercambio de información. 
f) En el diálogo deliberativo la situación inicial es el planteamiento de un dilema sobre una actuación práctica; el objetivo de las partes, coordinar con las demás los objetivos propios y las acciones para conseguirlos; y el fin del diálogo, decidir el mejor curso posible de acción.

g) En el diálogo erístico, es decir, en la riña, la situación inicial es la de un conflicto personal; el objetivo de las partes, atacar verbalmente al oponente; y la finalidad del diálogo, poner de relieve la base profunda del conflicto.

h) El diálogo institucional característico del funcionamiento de las instituciones inspirado en reglas de buen gobierno (Agustí, 2005) (Prats, 2005). La situación inicial es la convergencia de varias instituciones en un sector de actividades; el objetivo de las partes, desarrollar su propia actividad sin interferencia por parte de las otras; la finalidad del diálogo, lograr que la actividad de las instituciones intervinientes se desarrolle con coherencia fomentando sinergias y eliminando obstáculos.

i) El diálogo participativo propio del ejercicio de la autoridad en los sistemas democráticos. La situación inicial es la necesidad de desarrollar una determinada política o actuación por un órgano con autoridad para ello; el objetivo de las partes, imponer la actuación eliminando resistencias e impedirla o imponer su modificación, respectivamente; la finalidad del diálogo, hacer posible llevar a cabo la actuación en la forma más eficaz posible y con menos efectos negativos (García, 1985).

\section{DESARROLLO DE CASOS CON IDENTIFICACIÓN DE CRI- TERIOS INTERAMERICANOS}

\subsection{Discriminación por causa de género. Sentencia $N^{\circ}$ 292-16SEP- CC, Caso No 0734-13-EP, del 7 de septiembre de 2016}

Yesenia Iza Pilataxi, era bombera del cantón Archidona ${ }^{85}$ y fue despedida intempestivamente por Memorando $\mathrm{N}^{\circ}$ 001-CAD-CBA del 27

85 Contaba con un título de bombera profesional emitido por una institución autorizada. Era bombera profesional bajo el grado de subteniente, mediante la Resolución No 004 del 25 de marzo de 2010 del Consejo de Administración y Disciplina del Cuerpo de Bomberos Municipal de Archidona. 
de octubre de 2010 emitido por el Alcalde del cantón Archidona, José Toapanta Bastidas. El hecho que habría provocado la destitución irregular, según lo manifestó la accionante, fue su negativa de acceder a los favores sexuales que le solicitaba su exjefe, situación que fue comprobada en la respectiva causa penal.

Por el hecho del despido intempestivo, Yesenia Iza interpuso acción de protección considerando que se vulneró el derecho a la igualdad y no discriminación. Los jueces de primera y segunda instancia, negaron su petición. El juez que resolvió la primera instancia, consideró que, por no existir un contrato de trabajo no procedía la acción de protección. Además de que, a su criterio, no existía prueba de la discriminación. Por su parte, el juez de segunda instancia, consideró que el recurso de apelación no procedía por extemporáneo.

Frente a esta última decisión, Yesenia Iza interpuso acción extraordinaria de protección y la Corte Constitucional resolvió favorablemente, declarando la existencia de discriminación por categoría sospechosas, estas son,"criterios utilizados tanto por el Estado como por los particulares con miras a realizar diferencias que nunca parecerían justificarse y que en otros casos se presentan también como justificativos utilitaristas apelando a categorías como: el orden público, la moral pública, las buenas costumbres, etc.“.

En esta causa los jueces constitucionales utilizaron criterios de dos casos resueltos por la Corte IDH: Campo Algodonero versus México y Castro Castro versus Perú, así como de la Opinión Consultiva 18/03 del 17 de septiembre de 2003.

Los hechos de Castro Castro vs Perú, dan cuenta de un aparataje estatal creado con la finalidad de erradicar en su totalidad los elementos subversivos de la guerrilla en el Perú de los años noventa. El Presidente de la República del momento, Alberto Fujimori, luego del autogolpe de Estado había decidido entrar al penal Castro Castro y en este acabar con los ánimos partidarios de la célula terrorista de Sendero Luminoso. El resultado de la toma el penal fue de varios muertos y decenas de heridos. Entre ellos mujeres embarazadas quienes no solamente recibieron todo tipo de agresiones armadas, sino también fueron obligadas a permanecer boca abajo en el patio del penal (no obstante su estado de gestación) y en el traslado del penal fueron, a su vez, hacinadas con otros presos y llevadas sin el menor tipo de cuidado. Luego, en 
el hospital, las dejaron sin ropa durante quince días y fueron abusadas sexualmente por soldados que tenían el deber de protegerlas.

Por su parte, el caso Campo Algodonero versus México, trató sobre el derecho a la igualdad y no discriminación. En la ciudad de Juárez, México las mujeres entre 15 y 25 años de edad desaparecían y posteriormente sus cadáveres eran hallados con signos de violación sexual y tortura. Esto llevó a que se hable del Fenómeno de Juárez. Los familiares de las víctimas denunciaban su desaparición pero la Policía local contestaba frases discriminatorias haciendo alusión a su condición de mujer. Esta actitud de la Policía no quedaba únicamente en frases notoriamente discriminatorias sino que la decidia se mantenía durante la totalidad del proceso posterior al hallazgo de los cadáveres. Esto es que no se siguió el procediimento adecuado ni los protocolos correspondientes para el levantamiento del cadáver, custodia de la prueba, entrega del cadáver y posterior proceso judicial.

La razón principal por la que se tomaron estos dos casos como referencia, Castro Castro versus Perú y Campo Algodonero versus México, fue porque la CorteIDH encontró en ambos casos que los Estados partes de la Convención, Perú y México, respectivamente, no cumplieron con la prevención, protección y posterior sanción de los hechos discriminatorios por concepto de género. Con ello, las víctimas que acudieron a la Corte Interamericana de Derechos Humanos encontraron en sus decisiones, la reparacion a las violaciones de género perpetradas por el Estado.

¿Qué criterios interamericanos utilizaron?

- De la Opinión Consultiva No. 18/03, citaron el criterio que los Estados están obligados a adoptar medidas positivas para revertir prácticas discriminatorias existentes en sus sociedades en perjuicio de determinados grupos de personas.

- Del caso Castro Castro versus Perú, la Corte IDH sostuvo que los Estados están obligados a actuar con la debida diligencia en la investigación y sanción de tales hechos.

- En Campo Algodonero versus México, la Corte IDH señaló que las reparaciones a las víctimas debían adoptar una perspectiva de género y que deben tener una vocacion transformadora de dicha situacion, de tal forma que las mismas tengan un efecto no solo resolutivo sino también correctivo. 
- De los casos Castro Castro versus Perú y Campo Algodonero versus México señalaron que estos eran ejemplos de violación a la Convención Belem Do Paráar; que los Estados tenían, bajo la normativa de la Convención Interamericana, la obligación de prevención, reconociendo el derecho fundamental de todas las mujeres a una vida libre de violencia y además, resaltaron que el Estado, en casos de violencia de género, es responsable de la prevención, investigación y sanción.

Como situación inicial encontramos el dilema sobre la actuación práctica de los operadores judiciales de segunda instancia quienes, no obstante de tratarse de un caso de discriminación por causa de género bajo categoría sospechosas, decidieron no aceptar la acción de protección ni reparar la vulneración de los derechos vulnerados. Frente a ello, y tomando como referencia los criterios que la Corte IDH dio en los casos citados, la Corte Constitucional decidió favorablemente a Yesenia Iza Pilataxi. Primero, ordenando la restitución del trabajo a la perjudicada, con esto revirtieron las medida discriminatoria del despido. Segundo, la Corte Constitucional dispuso que los jueces deben generar confianza a la víctima de violencia de género. Un criterio opuesto al que manifestaron los jueces de instancia quienes negaron la acción de protección sin entrar a analizar la vulneración o no del Derecho. Con esto cumplieron el estándar internacional de la debida diligencia en la investigación y sanción de causas discriminatorias. Tercero, los jueces de la Corte Constitucional dispusieron se cree el Protocolo de Trabajo con visión de género para el Municipio de Archidona y se lleve a cabo la campaña de rechazo social de las agresiones de género que prevean medidas de protección a las víctimas. Con esto cumplieron el estándar relacionado a la obligatoriedad de los jueces de dictar decisiones con enfoque de género y que estos deben buscar, en la reparación, una forma de corrección de conductas discriminatorias. Cuarto, los jueces constitucionales para dar cumplimiento al estándar de la obligación de prevención que tiene todo Estado signatario de la Convención Americana y Convención Belém Do Pará, conminaron al cambio de patrones culturales. Mencionaron que "el cambio de patrones culturales es una tarea difícil, el primer paso lo deben dar las autoridades nominadoras de las instituciones públicas y privadas“.

86 Convención Interamericana para Prevenir, Sancionar y Erradicar la Violencia contra la Mujer, también conocida como Convención Belém do Pará. Define la violencia contra la mujer como "cualquier acción o conducta, basada en su género, que cause muerte, daño o sufrimiento físico, sexual o psicológico a la mujer, tanto en el ámbito público como en el privado". 
El objetivo de los jueces constitucionales frente al dilema inicial de la discriminación de género, fue declarar la vulneración del derecho a la igualdad y no discriminación, restituir el derecho vulnerado y prevenir la desviación de los operadores de justicia en casos análogos que a futuro se presenten en la judicatura. Demostrando con ello, la coordinación propia de un ejercicio de control convencional interno realizado por los jueces constitucionales. La finalidad del diálogo, al haber citado los criterios de Castro Castro versus Perú y Campo Algodonero versus México, fue la decisión del mejor curso posible de acción en el caso tratado y los juicios futuros de discriminación por causa de género.

Ahora, en cuanto al diálogo entre Corte Constitucional y los jueces de instancia que resuleven garantías constitucionales relacionadas con la discriminación por causa de género, la sentencia da cuenta de un diálogo participativo. La situación inicial plantea la necesidad de desarrollar una determinada actuación por un órgano con autoridad para ello y lo que busca es imponer o impedir una actuación determinada, o bien lograr una modificación de una actuación. En este caso, la Corte Constitucional hace un llamado de atención a los jueces que conocen asuntos de género, conminando a que den confianza a la víctima de estos asuntos y que al momento de resolver causas de este tipo, deberán decidir con una perspectiva de género. Logrando con ello una protección y no persecusión del aparataje judicial a la víctima de violencia de género. Con ello, la finalidad es conseguir una actuación eficaz y con menores efectos negativos a futuro en causas análogas.

\subsection{Asunto de persona privada de libertad en estado de gestación a quien se le negó el Habeas Corpus. Sentencia Na 247-17-SEP-CC, Caso $\mathrm{N}^{\circ}$ 0012-12-EP, del 9 de agosto de 2017}

La señora Sara Moya se encontraba en estado de gestación durante su detención. Ella solicitó la sustitución de la pena privativa de libertad al arresto domiciliario. Esto fue negado, ya que a criterio de los jueces de la Corte Nacional de Justicia "aquello constituye sustitución de la prisión, la misma que solo puede ser ordenada por el juez de garantías penales, en la etapa correspondiente y siempre que se demuestre oportunamente su estado de embarazo“. Como la Sra. Sara Moya al inicio del proceso penal no se encontraba embarazada sino que concibió en el tiempo que cumplía la pena, los jueces de la Corte Nacional de Justicia consideraron que su detención no era arbitraria, ilegal o ilegítima. 
Ahora bien, efectivamente, en un principio no se trataba de una detención contraria a las normas jurídica, pero eso no significa que la detención legal no pueda convertirse, durante el cumplimiento de la pena, en arbitraria, ilegal o ilegítima. Tales son los casos, por ejemplo, de las personas privadas de libertad que en ocasiones son torturadas en los centros de rehabilitación social. Si bien al tiempo del juicio la persona pudo ser detenida y posteriormente juzgada y sancionada, conforme a las normas del debido proceso, al momento de su detencion, por los actos de tortura, la privación de libertad se convierte en arbitraria y la víctima debe ser protegida. Por lo tanto, si una persona privada de libertad considera que su detención atenta contra la integridad física, por ejemplo en el caso de la tortura, bien puede solicitar un habeas corpus y el juez que sustancie la causa, está llamado a resolver sobre el Derecho Constitucional vulnerado y no, necesariamente, si su detención al inicio del proceso fue ilegal, arbitraria o ilegítima.

En este caso, la Corte Constitucional declaró vulnerado el derecho a la seguridad jurídica y al debido proceso por parte de los jueces de la Corte Nacional de Justicia porque los operadores judiciales al momento de resolver el habeas corpus debieron valorar si las condiciones en las que transcurría la privación de la libertad de Sara Moya, constituían o no, una violación o amenaza a su integridad física, que debían protegerse por medio de la acción de habeas corpus. Además, mencionó la Corte Constitucional que "el que una mujer embarazada pueda solicitar la sustitución de la medida de prisión ordenada en su contra por medio de un procedimiento ordinario, como es la solicitud ante el juez competente para tramitar el procedimiento o ejecutar la pena, no excluye per se la posibilidad de lograr dicha sustitución a través del habeas corpus".

\section{¿Qué criterios interamericanos utilizaron?}

La Corte Constitucional acogió la valoración que los jueces de la Corte IDH han hecho sobre el habeas corpus.

- Opinión consultiva OC-8/87 del 30 de enero de 1987 señaló que el habeas corpus debe verificar una real vulneración a los derechos a la libertad o integridad personal.

- La Corte Constitucional citó la Convención Americana de DD.HH., Art. 4.- Toda persona tiene derecho a que se respete su vida, a partir del momento de la concepción. 
- La Corte Constitucional manifestó que la mujer privada de la libertad en estado de gravidez es razón suficiente para considerar amenazada su vida y su integridad física, así como la protección del nasciturus, por el efecto de la privación de la libertad. Ello, a su vez, satisface el presupuesto de procedibilidad del habeas corpus, con lo cual los juzgadores que conocieron y resolvieron el recurso debieron dictar medidas sustitutivas a la prisión hasta 90 días después del parto.

Entonces, puede que la detención no sea arbitraria, ilegal o ilegítima, pero puede llegar a convertirse en tal sí dentro de la prisión se vulneran derechos fundamentales como es el caso. La Corte Constitucional agregó también que el habeas corpus es un derecho reconocido convencionalmente como herramienta para la lucha por la libertad y la integridad personal. Por lo tanto, el tipo de derechos sobre los que el operador jurídico que conoce la garantía jurisdiccional del habeas corpus, debe resolver, son precisamente la libertad y la integridad personal. Además, si se trata de una persona privada de libertad en estado de gestación, hay una protección especial al niño que está por nacer. Lo anterior se convirtió en regla jurisprudencial vinculante para casos futuros.

Entre la Corte Constitucional y la CorteIDH se dio un diálogo delibertativo cuya situación inicial era el dilema sobre cómo resolver un habeas corpus presentado por mujer embarazada para sustituir la pena de privación de libertad. En este caso también se constata la coordinación del criterio nacional de la Corte Constitucional con las opiniones convencionales sobre el habeas corpus y la protección del que está por nacer. La finalidad del diálogo era decidir el mejor curso posible de acción, que se consiguió al momento en que la Corte Constitucional declaró la vulneración del derecho a la seguridad jurídica y al debido proceso. Además, ordenó la reparación integral dejando sin efecto la sentencia de la Corte Nacional de Justicia, la orden de otorgar disculpas públicas a la perjudicada, de asegurar medidas de no repetición y de disponer al Consejo de la Judicatura la investigación, determinación de responsabilidades y sanción de los jueces que ordenaron en un principio la prohibición de sustitución de la medida sustitutiva a la prisión.

Además, se encuentra la existencia de un diálogo participativo entre la Corte Constitucional y los jueces que conocen las acciones de habeas corpus en los casos con el mismo patrón fáctico. La situación inicial es la de desarrollar una determinada actuación por parte de un órgano con autoridad para ello, los jueces que sustancian las acciones de 
habeas corpus, e imponiendo una actuación específica: "En concreto, el que una mujer embarazada pueda solicitar la sustitución de la medida de prisión ordenada en su contra por medio de un procedimiento ordinario, como es la solicitud ante el juez competente para tramitar el procedimiento o ejecutar la pena, no excluye per se la posibilidad de lograr dicha sustitución a través de la acción de habeas corpus si, como en el presente caso, se verifica que este procede, de acuerdo con su objeto establecido en la Constitución". Este criterio tiene como finalidad lograr una actuación eficaz de los operadores judiciales que decidan sobre el mismo patrón fáctico. Evitando con ello la continua generación de efectos negativos e imponiendo la modificación de la actuación inicial que fue lesiva de los derechos a la seguridad jurídica y el debido proceso.

\subsection{Asunto de despido de persona con enfermedad catastrófica. Sentencia N ${ }^{\text {a }}$ 375-17-SEP-CC, Caso N ${ }^{\circ}$ 0526-13-EP del 22 de no- viembre de 2017}

El 22 de octubre de 2012, el señor César Nogales presentó acción de protección en contra de PETROECUADOR por despido intempestivo. César Nogales era trabajador de PETROINDUSTRIAL, actual PETROECUADOR, desde el 1 de junio de 1988 y debido a la contaminación que se produce en dicho complejo industrial por la presencia de gases tóxicos, le detectaron dos enfermedades catastróficas graves. Dichas enfermedades las padece desde el año 2004 y tanto el juez de primera como de segunda instancia, negaron la acción de protección por considerarla un asunto de legalidad.

¿Qué criterios interamericanos utilizaron?

- El derecho a la salud reconocido en el Sistema Interamericano de Derechos Humanos. El artículo 10 del Protocolo de San Salvador está en consonancia con el artículo XI de la Declaración Americana, en el cual señala que el mencionado derecho debe ser garantizado por medio de "medidas sanitarias y sociales, relativas a la alimentación, el vestido, la vivienda y la asistencia médica, correspondientes al nivel que permitan los recursos públicos y los de la comunidad".

- A su vez, el artículo 26 de la Convención, reconoce la obligación directa de los Estados de promover el desarrollo progresivo y la no regresividad de los derechos económicos, sociales y culturales. 
- De lo anotado se evidencia que el derecho a la salud es un derecho que se articula sistemáticamente con otros derechos constitucionales, entre los que se destaca el derecho al trabajo, puesto que dentro del desarrollo de las diversas actividades laborales, se debe asegurar que las mismas no vayan en detrimento de la salud de las personas y de su vida, por lo que los trabajadores con afectaciones de tipo profesional merecen un trato diferenciado en razón de su particular situación, esto es, una enfermedad que tiene causa directa de la actividad laboral, de ahí que se desarrolle conceptos de protección para este grupo de personas, como la estabilidad laboral reforzada.

En cuanto a la estabilidad laboral reforzada la Corte Constitucional sostuvo que dadas las peculiaridades de determinados trabajadores se les debe brindar un trato preferente... lo que busca es superar aquellas desigualdades que necesitan ser protegidas para que se pueda hablar de una verdadera igualdad dentro de una sociedad plural atrasada por relaciones de poder.

- En cuanto a la reparación integral, la adopción de medidas de restitución a favor del accionante. La Corte Constitucional citó el caso Tibi versus Ecuador el cual establece un concepto de reparación integral a partir de la restitución de las cosas al estado anterior: "224. La reparación del daño requiere, siempre que sea posible, la plena restitución (restitutio in integrum), que consiste en el restablecimiento de la situación anterior. De no ser esto posible, como en el presente caso, el tribunal internacional debe determinar las medidas que garanticen los derechos conculcados, eviten nuevas violaciones y reparen las consecuencias que las infracciones produjeron, así como establecer la indemnización que compense por los daños ocasionados”.

Se encuentra en este caso, nuevamente, la existencia de un diálogo delibertativo, la situación inicial es la existencia de un dilema sobre una actuación práctica: el despido de una persona con enfermedad catastrófica y el objetivo de quienes participan en el diálogo, el de coordinar los objetivos a los parámetros del Protocolo de San Salvador, a la Convención Americana de Derechos Humanos y a la Constitución del Ecuador. La coordinación de criterios permitió tomar una decisión que significará darle un mejor curso posible de acción al despido de la persona con enfermedad catastrófica. Bajo la coordinación de criterios jurídicos convencionales se decidió a favor del perjudicado, con la declaración de la vulneración del derecho al trabajo y la debida reparación integral por el daño causando. 
En cuanto al diálogo entre la Corte Constitucional y los jueces nacionales, este fue de tipo participativo, porque impuso una actuación determinada con la finalidad de lograr, en casos futuros, una actuacion eficaz con menores efectos negativos a quienes plantean acciones en condiciones similares. Los jueces constitucionales señalaron que en en el futuro cuando los jueces de instancia conozcan casos con el mismo patrón fáctico, deberán cumplir la regla jurisprudencial siguiente: "Las personas portadoras de enfermedades catastróficas/profesionales gozan de un principio de estabilidad laboral reforzada merecedores de una especial protección; en tal virtud, no podrán ser separados de sus labores en razón de su condición de salud... los trabajadores que padecen enfermedades profesionales deberán tener acceso a la reubicación laboral en su medio de trabajo cuando el desempeño de sus actividades se vea mermado por su condición de salud“.

Con el dictamen de esta regla jurisprudencial los jueces impusieron para el caso concreto y los análogos, una actuación determinada que permita lograr una actuación más eficaz a favor de las personas con enfermedades catastróficas, evitando los efectos negativos de una postura contraria.

\subsection{Negativa del Instituto Ecuatoriano de Seguridad Social de atender a menor de edad por no ser hijo de abuelo, a pesar que este era afiliado del Instituto de Seguridad Social y ejercía la tute- la del niño- nieto. 22 de noviembre de 2017}

Un niño con discapacidad, diagnosticado con retardo mental, trastorno por déficit de atención, trastorno de conductas sociales y epilepsia requería de atención médica. En varias ocasiones el abuelo del menor, a cuyo cargo se encontraba porque la madre padecía de drogadicción, lo llevó al IESS para tratarlo por sus afecciones, pero cuando se derivó al especialista, el IESS se negó a prestar el servicio de salud al niño-nieto. La negativa del IESS se debió a que el niño-nieto no se encontraba considerado, según las disposiciones legales, dentro de los sujetos de protección del IESS. La ley no era extensiva a los nietos bajo custodia legal de los abuelos. Sobre estos hechos el abuelo presentó acción de protección, la que fue aceptada en primera instancia, pero revocada ante el juez de alzada. Por ello, el señor NN, abuelo del menor interpuso acción extraordinaria de protección que la Corte Constitucional aceptó. 
La Corte Constitucional consideró que los jueces que resolvieron el recurso de apelación, vulneraron el derecho a la salud del niño-nieto.

¿Qué criterios de la Corte Interamericana de Derechos Humanos utilizaron?

- Como fundamentos legales, los jueces de la Corte Constitucional citan el Art. 26 de la Convención Americana de Derechos Humanos, así como el Art. 10 del Protocolo de San Salvador y la Observación $N^{0} 14$ del Comité de Derechos Económicos, Sociales y Culturales. También citaron los artículos 32, 358, 359 y 363 de la Constitución de la República del Ecuador.

- Además, se citaron los casos en los que la Corte Interamericana de Derechos Humanos ha dado su criterio con relación al derecho a la salud y su relación con el derecho a la vida y la integridad física: Ximenes López versus Brasil; Albán Cornejo versus Ecuador; Furlán vs Argentina; Furlan versus Argentina; y, Suárez Peralta versus Ecuador, el estándar señalado en la jurisprudencia de la Corte Interamericana es que: “... el derecho a la vida es un derecho humano fundamental cuyo goce pleno constituye una condición para el ejercicio de todos los derechos. La integridad personal es esencial para el disfrute de la vida humana. A su $v e z$, los derechos a la vida y a la integridad personal se hallan directa e inmediatamente vinculados con la atención de la salud humana".

- El estándar que demuestra la interdependencia entre los derechos humanos, sobre todo en tratándose de derechos sociales los que han sido difícilmente judicializados y protegidos. La salud como derecho y como servicio público resultan ser interdependientes, esto significa que el sistema que garantiza el servicio de salud no puede desconocer la existencia y prevalencia del derecho a la salud. El servicio público de salud es la estrategia institucional para realizar el mencionado derecho. El derecho a la salud como servicio público implica el acceso oportuno, eficaz, de calidad y en igualdad de condiciones a todos los servicios, facilidades, establecimientos y bienes que se requieran para garantizarlo.

- Cuando se trata de menores de edad, a criterio de la Corte Constitucional, citando el caso Furlán y Familiares versus Argentina y Gonzáles Lluy y otros versus Ecuador, el derecho a la salud cobra mayor relevancia, toda vez que se trata de sujetos que por su temprana edad y situación de indefensión requieren de especial protección. 
En tanto el derecho a la salud de los niños, de conformidad con lo establecido en el artículo 44 de la Constitución, por tener el carácter de "constitucional y humano", debe ser protegido de forma inmediata. (...) los niños al ser parte de las personas de atención prioritaria, en tanto al ser considerados grupos vulnerables ostentan una protección reforzada a la hora de garantizarse sus derechos, entre ellos el derecho subjetivo a la salud.

- Para los jueces constitucionales el derecho a la salud consagra tres obligaciones para el Estado: la obligación de respetar, la obligación de proteger y la obligación de cumplir. Esta última consagra la obligación de facilitar, proporcionar y promover el acceso al derecho, así como la adopción de medidas legislativas.

- Con base al principio pro ser humano, en caso que existan dudas en torno a si el servicio se halla excluido o incluido dentro de aquellos previstos en el régimen de coberturas, ha de prevalecer una hermenéutica que favorezca la prestación efectiva del mismo, y más aún si el servicio tiene que ser prestado a una persona en doble situación de vulnerabilidad, niño-persona con discapacidad.

- Además, el niño-nieto padecía de epilepsia. Una enfermedad crónica que requiere de atención médica especializada, así como de chequeos médicos continuos para entender que se ha respetado el principio del interés superior del niño. Bajo el criterio de los jueces constitucionales, el IESS al aplicar el artículo 102 de la Ley de Seguridad Social, para suspender la atención médica al niño-nieto dejó de lado los preceptos constitucionales y esto representa una regresividad en lo que respecta el derecho a la salud y a la atención y cuidado de niñas y niños.

- La Corte, nuevamente, citó el criterio de la Corte Interamericana de Derechos Humanos en el caso Cuscul Piraval y otros, señalando la imposibilidad de efectuar un análisis global sobre la regresividad a partir de un grupo reducido de personas. Sin embargo, se indicó que: “... cuando se trata del derecho a la salud hay una obligación de cumplimiento progresivo, $y$ esto se refiere al derecho a la salud en general, tanto curativa como preventiva y cuya atención es debida a toda la población", es decir existe una situación de exigibilidad inmediata de este derecho en relación con el principio de no-discriminación, en el sentido que el Estado no puede garantizar el derecho a la salud de manera discriminatoria. 
Por su parte, la Corte aclaró que nadie puede ser discriminado por cualquier distinción personal o colectiva, temporal o permanente que tenga por objeto o resultado menoscabar o anular el reconocimiento, goce o ejercicio de los derechos. La inclusión de estos criterios se ha denominado categorías o criterios sospechosos. Para identificar la categoría sospechosa, es necesario tener presente: i) aparecen como categorías prohibidas en el texto constitucional, artículo 11 numeral 2 CRE; ii) restringen derechos constitucionales; y que, iii) generalmente afectan de manera desfavorable a minorías o grupos sociales que se encuentran en estado de debilidad manifiesta y que requieren especial protección por parte del Estado.

Además, la suspensión del servicio de atención médica de un menor con discapacidad intelectual es un hecho cierto, para lo cual el IESS argumentó la aplicación del artículo 102 de la Ley de Seguridad Social, en la que se determina que la cobertura del servicio no es extensiva para los nietos del afiliado, producto de lo cual el niño-nieto se ha visto gravemente afectado. Así se colige el cumplimiento de los tres parámetros para identificar la categoría sospechosa.

Por ello se evidencia, a criterio de la Corte Constitucional, que al niño-nieto se le vulneró el derecho a la salud en la sentencia de segunda instancia dentro de la acción de protección $N^{\circ}$ 01904-2016-00020 dictada por la Sala Penal de la Corte Provincial de Justicia del Azuay el 30 de septiembre de 2016. Porque los jueces provinciales no realizaron el respectivo análisis de la actuación del IESS al negar la atención del mencionado niño sin considerar su situación de doble vulnerabilidad, sin estimar que este se encuentra bajo custodia de un afiliado, sin el examen de lo que implica el derecho a la salud y sin atender los criterios jurisprudenciales convencionales.

Se identifica la existencia de un diálogo deliberativo entre la Corte Constitucional y la Corte Interamericana. Al ser la situación inicial un dilema sobre la extensión o no del servicio público de salud a un niño nieto de un afiliado que ejerce la tutela del menor. Los criterios convencionales permitieron coordinar las acciones futuras para lograr la cobertura de salud en este mismo tipo de situaciones. Logrando con ello, una decisión favorable que propone un mejor curso posible de acción en casos futuros.

En cuanto a la Corte Constitucional y, en este caso, la función legislativa, se dio un diálogo participativo. La situación inicial que plantea- 
ba el Art. 120 de la Ley de Seguridad Social no permitía la cobertura del servicio de salud a los nietos de afiliados que ejercen la tutela del menor. El objetivo en este caso fue imponer una modificación de ley, de manera que lograron una actuación eficaz del Instituto Ecuatoriano de Seguridad Social, que produjera menores efectos negativos a futuro en casos análogos.

\subsection{Despido de una persona con discapacidad. Sentencia $\mathrm{N}^{\mathrm{a}}$ 004-18-SEP-CC, Caso N. ${ }^{\circ}$ 0664-14-EP, del 3 de enero de 2018 por el que una persona con discapacidad, por su condición, fue despedi- da intempestivamente de la Agencia de Tránsito del Ecuador}

La señora Zurkaya Robalino Flores trabajaba dentro de la Agencia de Tránsito del Ecuador y fue despedida intempestivamente. Ella tenía un grado de discapacidad del $50 \%$ y, a pesar de ello, según relató en su demanda de acción de protección, había sido discriminada en su trabajo por medio de tratos descorteces, altaneros y abusivos por parte de sus superiores. Su jefa le dispuso desarrollar actividades laborales en el archivo de la institución y, al mismo tiempo, sin considerar su discapacidad física, le ordenó trabajar en ventanilla de atención al público. Al no poder realizar correctamente ambas tareas, no le renovaron el contrato y fue despedida. Frente a esto, Zurkaya Robalino presentó acción de protección, la misma que fue negada tanto en primera instancia como en segunda instancia. Luego de lo cual, la perjudicada interpuso acción extraordinaria de protección que la Corte Constitucional resolvió a su favor.

¿Qué criterios interamericanos utilizaron?

- La Corte Constitucional, citó los casos Velásquez Rodríguez versus Honduras y Usón Ramírez versus Venezuela, en los que la Corte Interamericana de Derechos Humanos reconoce el principio iura novit curia, criterio a través del cual el juzgador tiene la facultad e inclusive el deber, de aplicar las disposiciones jurídicas pertinentes en una causa, aún cuando las partes no las haya invocado expresamente.

- Luego, la Corte Constitucional citó el caso Lagos del Campo versus Perú a propósito del derecho al trabajo: Párr. 147: En este sentido, el Comité de Derechos Económicos, Sociales y Culturales en su Observación General No. 18 sobre el derecho al trabajo, expresó que "implica el derecho a no ser privado injustamente del empleo". 
Asimismo, ha señalado que el "incumplimiento de la obligación de proteger se produce cuando los Estados partes se abstienen de adoptar las medidas adecuadas para proteger a las personas sometidas a su jurisdicción contra las vulneraciones del derecho al trabajo imputables a terceros", lo cual incluye "el hecho de no proteger a los trabajadores frente al despido improcedente".

"Cabe precisar que la estabilidad laboral no consiste en una permanencia irrestricta al puesto de trabajo, sino implica respetar este derecho, entre otras medidas, otorgando debidas garantías de protección al trabajador a fin que, en caso de despido se realice este bajo causas justificadas, lo cual implica que el empleador acredite las razones suficientes para imponer dicha sanción con las debidas garantías y frente a ello el trabajador pueda recurrir tal decisión ante las autoridades internas, quienes verifiquen que las causales imputadas no sean arbitrarias o contrarias a derecho".

- Además, la Corte Constitucional tuvo en cuenta que la sentencia de la Corte Interamericana de Derechos Humanos, de 31 de agosto de 2017, establece un estándar mínimo de protección contra terminaciones de la relación laboral que resulten injustificadas o improcedentes. Conforme lo reconocido en la Constitución de la República del Ecuador, la Convención sobre los Derechos de las Personas con Discapacidad y la Ley Orgánica de Discapacidades en particular en su Art. 51, el cual dispone que las personas con discapacidad gozan de un régimen de protección especial al derecho al trabajo, así como a las garantías de estabilidad laboral.

Conforme a la Convención sobre los Derechos de las Personas con Discapacidad, el Estado ecuatoriano, además de tener la obligación de garantizar el derecho al trabajo a las personas con discapacidad, deberá velar, entre otras consideraciones, por su estabilidad laboral o condición de continuidad: Art. 27 Trabajo y Empleo: 1. Los estados partes reconocen el derecho de las personas con discapacidad a trabajar, en igualdad de condiciones con las demás, ello incluye el derecho a tener la oportunidad de ganarse la vida mediante un trabajo libremente elegido o aceptado en un mercado y un entorno laborales que sean abiertos, inclusivos y accesibles a las personas con discapacidad. Los estados partes salvaguardarán y promoverán el ejercicio del derecho al trabajo, incluso para las personas que adquieran una discapacidad durante el empleo, adoptando medidas pertinentes, incluida la promulgación de legislación, entre ellas: a) Prohibir la discriminación por 
motivos de discapacidad con respecto a todas las cuestiones relativas a cualquier forma de empleo, incluidas las condiciones de selección, contratación y empleo, la continuidad en el empleo, la promoción profesional y unas condiciones de trabajo seguras y saludables. Por lo que, conforme las disposiciones consagradas en la Constitución, así como en Convenios Internacionales, las personas con discapacidad tienen, entre otros derechos, el de trabajar en condiciones de igualdad de oportunidades, en un marco de estabilidad laboral, que permita alcanzar la realización económica y personal de este grupo de personas con derecho a recibir atención prioritaria.

Respecto al deber del Estado de garantizar el derecho al trabajo y de proteger al trabajador del despido improcedente, es valioso el aporte que en el caso Lagos del Campo versus Perú hacen los jueces de la Corte Interamericana de Derechos Humanos y que recoge la Corte Constitucional del Ecuador, cuando menciona que: "Lo improcedente no es el despido sino hacerlo por causas arbitrarias o contrarias a Derecho". El despido debe realizarse bajo causas justificadas y que el trabajador pueda recurrir tal decisión ante las autoridades internas del lugar donde labora.

En cuanto a lo ordenado en el Convención sobre los Derechos de las Personas con Discapacidad, la sentencia recordó que, frente a una persona con discapacidad, el Estado debe garantizar: su derecho al trabajo, a la estabilidad y a la condición de continuidad. Por ello, la Corte Constitucional, para hacer cumplir el derecho al trabajo, estimó que la accionante sea restituida a su puesto, bajo la modalidad de contrato de servicios ocasionales. Para hacer cumplir los requisitos de estabilidad y condición continuada, dispuso que la accionante tenga el contrato de servicios ocasionales hasta que la institución pública realice, en el menor tiempo posible, el respectivo concurso de méritos y oposición que permita a la legitimada activa participar en este y tener la oportunidad de ingresar en el servicio público. Por último, se dispuso realizar en la Agencia de Tránsito del Ecuador una capacitación en materia de los derechos de las personas con discapacidad.

Entre la Corte Constitucional y la Corte Interamericana se dio un diálogo deliberativo. Se identificó como situación inicial un dilema respecto a la procedencia o improcedencia del despido de una persona con discapacidad. Los jueces constitucionales consideraron que no procede el despido de personas por su condición de discapacidad porque tal hecho es discriminatorio. La finalidad del diálogo logró reconocer la estabilidad laboral reforzada de las personas con discapacidad. 
Entre los jueces constitucionales y los jueces de instancia que conocen acciones de protección sobre el mismo patrón fáctico, se dio un diálogo participativo al imponer un criterio que modifica su actuación judicial. Porque conmina a los operadores judiciales a resolver sobre la vulneración o no de derechos constitucionales dentro de garantías jurisdiccionales y porque constituye, asimismo, un precedente aplicable en casos futuros análogos.

\section{CONCLUSIONES}

En el diálogo deliberativo la situación inicial es el planteamiento de un dilema sobre una actuación práctica; el objetivo de las partes, coordinar con las demás los objetivos propios y las acciones para conseguirlos; y el fin del diálogo, decidir el mejor curso posible de acción.

En el diálogo participativo la situación inicial es la necesidad de desarrollar determinada política o actuación por un órgano con autoridad para ello. El objetivo es imponer una actuación, imponer una modificación o impedir una actuación. La finalidad, es lograr una actuación eficaz y con menores efectos negativos.

Se puede afirmar que, en los cinco casos planteados, entre la Corte Constitucional del Ecuador y la Corte Interamericana de Derechos Humanos existió un diálogo deliberativo. Al ser la situación inicial el enfrentarse al dilema de la vulneración de derechos constitucionales y logrando, con base a los criterios progresivos y de protección dados en las sentencias interamericanas, la coordinación de criterios y decisión en el sentido más favorable.

En el litigio de género acoge el innovador criterio interamericano de la reparación correctora; en el caso de género, se obliga a los jueces que conocen causas de violencia contra la mujer a fallar con enfoque de género; en el asunto de la mujer embarazada privada de libertad, dicta la regla jurisprudencial de protección del nasciturus; en la causa del trabajador con enfermedad profesional, establece la regla interpartes y proteccionista de la estabilidad laboral reforzada; en la causa del niño-nieto se reformó el artículo 120 de la Ley de Seguridad Social para que exista cobertura a los nietos de afiliados cuya tutela ejercen; y, por último, en el caso de la persona con discapacidad despedida, señaló el claro criterio que las personas con discapacidad gozan de un régimen de protección especial del derecho al trabajo y que al momento de despedir a 
una persona, el empleador debe hacerlo por causas justificadas, acreditar razones suficientes para imponer dicha sanción y el trabajador debe poder recurrir tal decisión ante las autoridades internas.

Por su parte, el diálogo entre la Corte Constitucional y los operadores judiciales, se lo puede calificar de participativo. Ya que, modificó la situación inicial que lesionaba los derechos constitucionales e impuso una modificación en la actuación de los jueces de instancia que a futuro conozcan casos similares. Logrando con ello una actuación eficaz y con menores efectos negativos que los dados anteriormente.

\section{REFERENCIAS BIBLIOGRÁFICAS}

Asociación de Letrados del Tribunal Constitucional. (2013). Tribunal Constitucional y diálogo entre tribunales. XVIII Jornadas de la Asociación de Letrados del Tribunal Constitucional. Madrid: Centro de Estudios Políticos y Constitucionales.

Agustí, C. (2005). La gobernanza hoy: 10 textos de referencia. España: Estudios goberna.

Corte Nacional de Justicia (2016) Caso de discriminación por causa por género, 0734-13-EP

Cabrera y Carrazco Montalvo. (2016). Los principios de igualdad y no discriminación, Principios Constitucionales, Tomo I. Quito: Editorial Jurídica Cevallos.

García, M. (1985). Las transformaciones del Estado contemporáneo. Madrid: Alianza.

Prats, J. (2005). De la burocracia al management. Del management a la gobernanza. Las transformaciones de las Administraciones públicas de nuestro tiempo. Madrid: Instituto Nacional de Administración. 


\section{Base Legal}

Corte Constitucional (2018) Sentencia 004-18-SEP-CC, Caso 066414-EP (Corte Constitucional del Ecuador 03 de Enero de 2018).

Corte Constitucional (2017) Sentencia 247-17-SEP-CC, Caso $0012-$ 12-EP.

Corte Constitucional (2017) Sentencia 247-17-SEP-CC, Caso 001212-EP.

Corte Constitucional (2017) Sentencia 292-16-SEP-CC, Caso 073413-EP

Corte Constitucional (2017) Sentencia 375-17-SEP-CC, Caso 052613-EP).

Recibido: 9 de septiembre de 2018

Aceptado: 19 de noviembre de 2018

Verónica Hernández Muñoz, Mgtr.: Docente titular UEES

Correo electrónico: vlhernandez@uees.edu.ec 